\title{
Mobile Phone Use and Risk of Thyroid Gland Lesions Detected by Ultrasonography
}

\author{
Naglaa M. Elsayed1,2, Saddig D. Jastaniah1 \\ ${ }^{1}$ Diagnostic Radiology Department, King Abdulaziz University, Jeddah, Saudia Arabia \\ ${ }^{2}$ Diagnostic Radiology Department, Faculty of Medicine, Cairo University, Cairo, Egypt \\ Email: www.sjastaniah@kau.edu.sa
}

Received 19 May 2016; accepted 18 June 2016; published 21 June 2016

Copyright (C) 2016 by authors and Scientific Research Publishing Inc.

This work is licensed under the Creative Commons Attribution International License (CC BY).

http://creativecommons.org/licenses/by/4.0/

c) (i) Open Access

\begin{abstract}
In recent years, widespread use of mobile phones has led to a public debate about possible harmful effects on human health. A lot of researchers studied the possible effect of radiofrequency energy (RFE) emitted from cell phones on the human body. Up to our knowledge no one studied the effect of these waves on the thyroid gland by Ultrasonography (US). Our aim was to investigate the possible effects of EMR arising from cell phones on the thyroid gland using US. A prospective study was done on 180 participants, 110 females and 70 males, ranging in age from 15 to 65 . A constructed questionnaire was distributed among them before performing US of the neck. Demographic data along with US findings were collected and statistically analyzed. A total of $46.7 \%$ of our participants had abnormal findings of the thyroid gland more in non smart phone users and more in females. The commonest abnormality was multinodular goiter (54\%). Expanded researches are still needed to answer the question about the hazards of RFE on human health. All efforts should be made to encourage users of cellular phone to follow mobile device recommendations of manufacturers and avoid its possible hazards as possible.
\end{abstract}

\section{Keywords}

Radiofrequency Energy, Mobile Phones, Ultrasound, Thyroid Gland, Nodules

\section{Introduction}

Radiofrequency energy is a form of EMR which can be categorized into two types: ionizing (e.g., X-rays, radon, and cosmic rays) and non-ionizing (e.g., radiofrequency and extremely low frequency, or power frequency). Exposure to ionizing radiation, such as from X-rays, is known to increase the risk of cancer. However, although many studies have examined the potential health effects of non-ionizing radiation from radar, microwave ovens, 
cell phones, and other sources, there is currently no consistent evidence that non-ionizing radiation increases cancer risk [1].

The biological effects of the mobile phones on the human body are extensively studied. Studies included the heating effects of EMR [2] [3], changes of the glucose metabolism of the adjacent structures [4] [5], alteration of the blood flow to the brain [6] or even induction of cancer formation. The INTERPHONE research which described data from 13 countries was the biggest and extensive study of the use of mobile phone up till now [7]. On the other hand, it was reported that radiofrequency waves being part of EMR has insufficient ionization energy to molecules and is unable of direct damage to DNA excluding their ability to lead to cancer formation [8].

Recently, it was estimated that more subscribers joined services of the mobiles devices including tablets and cell phones which reached above 300 million in the USA, and worldwide subscribers became more than 6 billion peoples [9]. Teenage and many children became heavily using cellular phone [10]. In general, the biological effects of EMR on children could reach higher than that of adults up to several times as has been investigated [11].

In a study by United Nations Conference on Trade and Development [12], Saudi Arabia occupies the first rank among the countries with the highest proportion of mobile phone users in the world with a ratio of 188 percent, followed by Vietnam and Oman in the second and third places respectively. The percentage is by far the highest when compared to the other Arab Gulf states.

Thyroid diseases are very common in the clinical practice. Thyroid hormone dysfunction is considered (with diabetes mellitus) to be the commonest endocrine pathologies worldwide. In Saudi Arabia, thyroid diseases are very common. Many literatures mentioned increased incidence of thyroid lesions in many areas along Saudi Arabia. Others found increased prevalence of thyroid cancer among Saudi females, with the male to female ratio is 0.3:1 [13]. From these two points, we got the idea of correlating thyroid disorders to the use of mobile phones in Saudi Arabia. Many literatures have studied the relation of thyroid disorders to many factors such as nutritional factors, age, gender, vitamin D deficiency, diabetes mellitus or many other factors. To our knowledge and after extensive search, there is no previous research that studied the possible relation between thyroid diseases and mobile phones using ultrasonography.

\section{Patients and Methods}

\subsection{Study Plan}

After obtaining ethical approval, a prospective study was done at the diagnostic radiology department, Faculty of Applied Medical Sciences, King Abdulaziz University.

\subsection{Subjects}

One hundred, eighty participants were involved in this study, 110 females and 70 males, ranging in age from 15 to 65 with the mean age is 40 years. Subjects were recruited from the following sources; volunteers from the college students, staff and some specialty clinics at KAU. A questionnaire was distributed to each subject, and filled in aided by one of the project participants.

\subsection{Ultrasound Examination}

Ultrasound examination of the thyroid gland was done as follows:

Machine: Phillips IU22 and Phillips HD3.

Subject's position: All examinations were done with the subject in the supine position, neck hyper extended with a pillow under the neck.

Transducer: Examinations were done by a specialist radiologist or sonographer using 5 - $9 \mathrm{MHz}$ linear probe under complete hygienic conditions.

US technique: The examination was started by grey scale US in the B mode. Real time scanning was done for both lobes as well as the isthmus in axial and sagittal plans.

The antero-posterior, transverse and sagittal diameters of each lobe, as well as the antero-posterior diameter of the isthmus were taken on freeze images. For any abnormality detected, full analysis of its US criteria was done.

Then Color Doppler mode was applied to study the vascularity of the gland, and of lesions, if any. 
Examination of the carotid sheaths on both sides was done especially in cases of thyroid enlargement to detect any vascular compression. Examination of the cervical lymph nodes was done to detect lymph node enlargement or infiltration, as well as abnormal vascularity.

\subsection{Image Interpretation}

Images were electronically stored, revised by the Radiology consultant of the project and then confidentially discussed with the patients.

Every case was analyzed regarding the following points:

- Size, echogenicity and vascularity of the whole gland.

- Presence of focal lesions, their number, size of the largest, echogenicity, borders, shape, halo sign, vascularity and calcification.

- Presence of abnormal lymph nodes.

\subsection{Statistical Analysis}

Patients were categorized into 2 groups regarding using smart phones. Categorical variables were presented by number and percent. Association between using smart phones and other parameter was done by Chi-square or Fischer's exact test, if appropriate. Odds ratio(s) (OR) with 95\% confidence interval (CI) were also calculated. Odds ratio is index that calculated to assess the probability of occurrence of an event in presence of certain risk. BMI in the 2 groups was compared by t-test.

In all test, $\mathrm{p}$ value was considered significant if less than 0.05 .

\section{Results}

Demographic analysis of our study group showed that 141 were using smart phones and 39 were using non smart phones with the p value $=0.01$. For both types, females users were more than males $(61.1 \%$ : $38.9 \%)$ respectively. The commonest age group was 20 - 30 years (45\%), and the least age group was participants $>60$ years old. Regarding marital status, single participants were much more than others (68.8\%). school students used smart phones almost equal to college students.

Most participants (44.6\%) use mobile phones from 5 - 10 years, and 36.7\% use mobile phone (calls and non-calls) for more than 5 hours daily. A total of $52.5 \%$ don't use head phones and $70.1 \%$ leave phone by side during sleep. Non smart phone users spend $<1$ hour for total use/day and do not use headphones or speakers as much as smart phone users.

Studying the medical condition of all participants showed that non smart phone users experienced weakness, fatigue, HTN more than smart phone users with a significant $p$ value $(<0.01)$.

Figure 1 shows the number of smart and non-smart phone users who had abnormal US of the thyroid gland. It is noticed that $46.7 \%$ had abnormal thyroid gland and 53.3\% had normal thyroid US. Comparing abnormal thyroid gland between smart and non-smart phone users showed that non smart phone is significantly associated with thyroid disease much more than smart phone (79.5\%: 20.5\% respectively).

From this figure we can also find that the number of cases using smart phone with thyroid disease is much less than cases with normal thyroid.

$\mathrm{OR}=0.15$ (95\% CI $0.07-0.36)$. OR is less than 1 , means there is no increased risk of thyroid disease on using smart phones

This means smart phone is not blamed for thyroid disease or let's be accurate; it is not associated with thyroid disease. This relationship does not mean cause-effect, it is an association. A long term study is needed to study the effect of mobile phone on each thyroid abnormality individually.

Analysis of demographic data of cases using mobile phones and had abnormal thyroid gland shows:

- Females have abnormal thyroid status more than males with $\mathrm{p}$ value $<0.01$;

- Abnormal thyroid status prevalent more in age 20 - 50 years with $p$ value $<0.01$;

- Abnormal thyroid in married more than single population with $\mathrm{p}$ value $<0.01$;

- Abnormal thyroid was associated with longer use of smart phones daily with p value $=0.02$;

- Abnormal thyroid cases use headphones speakers is less than abnormal thyroid cases not using it with p value $<0.01$; 


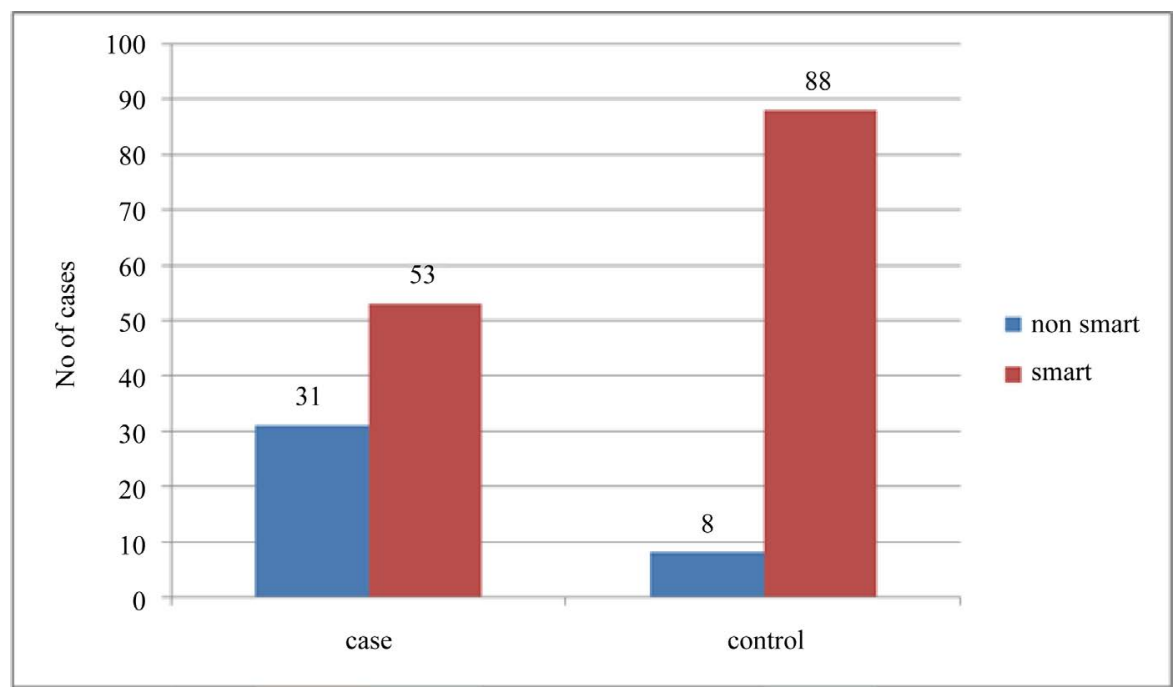

Figure 1. Thyroid diseases detected by US in smart phone and non-smart phone users.

- $\mathrm{OR}=2.6$ (95\% CI 1.3 - 5.2) Since OR > 1, this means that not using head phones increase the risk of thyroid abnormalities 2.6 times more in the exposed patients to smart phone without using headphones.

Patients with abnormal thyroid have history of thyroid disease, fatigue, arrhythmia, weight loss and rheumatic disease more than pts with normal thyroid. This is more with non-smart phones users.

Only 68 (34 out of 114 using smart phones and 15 out of 39 using non smart phones) participants had thyroid function tests. Most cases showed normal functions, and for abnormal cases hypothyroidism was more than hyperthyroidism. No significant difference in thyroid function test between smart phone users and non-smart phone users as shown in Figure 2.

Still there is no significant association between abnormal thyroid function and use of mobile phones.

\section{US Findings of the Thyroid Gland in the Study Groups}

The commonest detected abnormality was simple nodular goiter (SNG) (54\%), followed by cysts $28 \%$, then thyroiditis (12\%) and nodules was the least finding (6\%) (Figures 3-5).

\section{Discussion}

In our study, thyroid function tests were abnormal in $29.4 \%$ of smart phone users and $13.3 \%$ of non-smart phone users who had the tests. Most of them showed low hormonal profile with increased TSH. Some studies observed a higher than normal TSH level, low mean T4 and normal T3 concentrations in mobile users. It seems that minor degrees of thyroid dysfunction with a compensatory rise in TSH may occur following excessive use of mobile phones. It may be concluded that possible deleterious effects of mobile microwaves on hypothalamic-pituitarythyroid axis affects the levels of these hormones [14]. In another study, an in vitro evaluation of non-ionizing electromagnetic radiation (NIER) effects on human thyroid cells was done. Their results indicated that $900 \mathrm{MHz}$ EMF emitted by cellular telephones decrease serum TSH and T3 - T4 levels [15].

Referring to the fact that hypothyroidism and hyperthyroidism are very common in Saudi population [16] [17] and referring to the other fact that the number of mobile phone users is escalating, and the trend is chiefly driven by the widespread use of the Internet in the Saudi community, the study said [12], we can add prolonged mobile phone use as an additional risk factor to widespread of thyroid diseases among Saudi population. Risk factors of thyroid diseases in Saudi population, hypothyroidism patients psychic, congenital and diabetes showed significant increase in males in compared with females. Also autoimmune thyroidoitis (Hashimoto thyroiditis, Grave disease) and malignant thyroid were significant $(\mathrm{p}<0.05)$ in males. On the other hand, bad nutrition, iodine deficiency, goiter and benign thyroid cancer were significantly increased in females comparable with males. In hyperthyroidism patients, iodine deficiency, and benign and malignant thyroid cancer revealed significant increase in males, while bad nutrition and goiter were significantly increased in females [17]. 


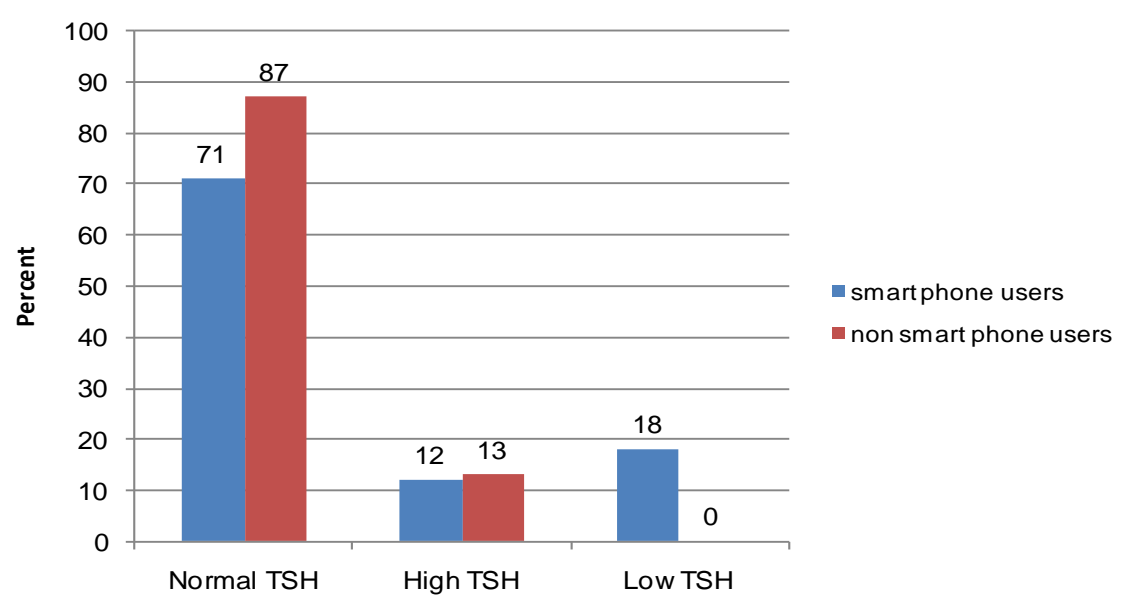

Figure 2. Results of thyroid function test in both study groups.

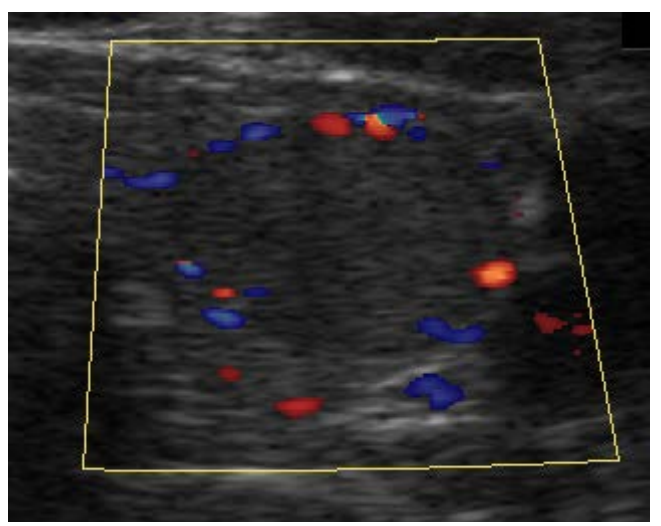

Figure 3. Doppler US shows benign looking nodule with halo sign and peripheral vascularity.

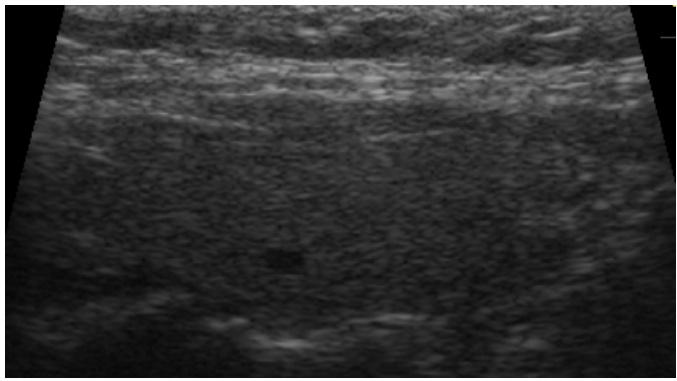

Figure 4. Grey scale US shows simple thyroid cyst.
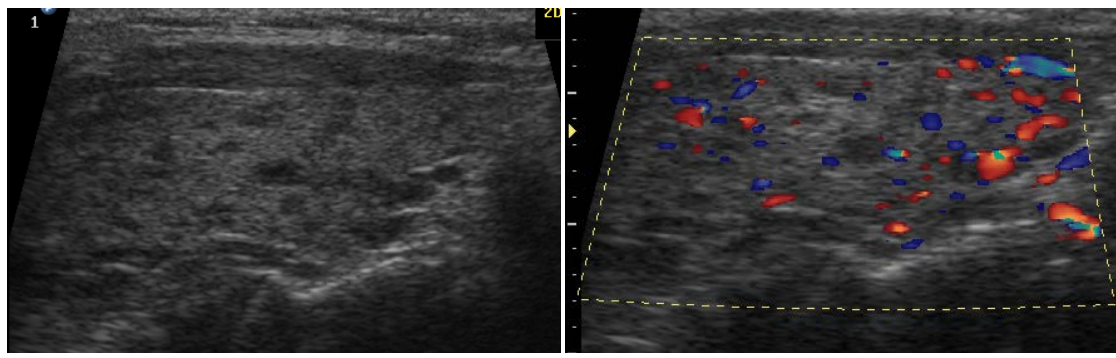

Figure 5. Grey scale US and Doppler show diffuse thyroiditis with heterogeneous, hypevascular gland. 
Electromagnetic radiation may not only cause thyroid dysfunction with alteration of the thyroid hormones level —but also it may have neoplastic effect on the gland itself. The scientific community is divided as to the connection between cellular radiation and cancer. One opinion is that because cellular radiation is non-ionizing and incapable of causing changes in cellular DNA, it cannot cause cancer. It is generally accepted that damage to DNA is necessary for cancer to develop. However, radiofrequency energy, unlike ionizing radiation, does not cause DNA damage in cells, and it has not been found to cause cancer in animals or to enhance the cancercausing effects of known chemical carcinogens in animals [18]. But in recent years evidence has mounted from epidemiological studies indicating a relationship between increased exposure to cellular radiation and cancerous growths, especially in the brain and the salivary glands and other structures of the head and neck.

In our study, abnormal thyroid gland was detected by US in $46.7 \%$. The commonest detected abnormality was simple nodular goiter (SNG) (54\%), followed by cysts $28 \%$, then thyroiditis (12\%) and nodules was the least finding (6\%).

It seems that thyroid abnormalities are affected by the type of mobile phone. Cases using non smart phone have more abnormality than cases using smart phone. We refer this to the fact that new generations of mobile phones generate less EMW.

The duration of using mobile phones has also affected our results. Cases that use the phone for longer duration are affected more. In a study of Lonn S et al., he stated that "Our findings do not indicate an increased risk of acoustic neuroma related to short-term mobile phone use after a short latency period. However, our data suggest an increased risk of acoustic neuroma associated with mobile phone use of at least 10 years' duration" [19].

We had 4 cases with suspicious nodules and/or LN that carried malignant criteria and they were referred to the hospital for further evaluation. This means that electromagnetic radiation may have a carcinogenic effect on the thyroid gland but, due to the small number of cases, a larger Cohort study is needed for more accurate a proliferative effect of NIER on human thyrocytes was suggested, an effect that may link NIER exposure with potential carcinogenesis [20].

In our study, using head phones and speakers reduces the biological effect of EMW on the nearby tissues. In a study of Hilly et al., they mentioned that "The thyroid gland is located in the neck, but the area is located the same distance from the ear as the regions of the brain where [cancerous] growths have been diagnosed as being related to the use of the [cellular] devices. This is a region that is not far from the center of the device's radiation," [21].

\section{Conclusions}

About half of our participants had one or more abnormal US of the thyroid gland. Although our results are not statistically significant, yet, it is to be considered. Most cases showed clinically insignificant thyroid changes like small cysts or benign looking nodules. However, few suspicious nodules were also detected that warranted further evaluation. Yet no direct correlation may be determined unless a long term study is conducted to identify the effect, if any, of mobile phones on each thyroid abnormality individually.

Although there is not conclusive evidence regarding the hazardous effects of EMW emitted from mobile phones on humans, yet, many researchers found alarming results that linked the extensive use of mobile phones for a long duration with direct skin contact and the development of some types of neoplasms of the head and neck structures. Until more data are obtained, all efforts should be made to encourage users of cellular phone to follow mobile device recommendations of manufacturers and avoid its skin contact as possible. We recommend further extensive studies including larger sample volume to get more documented results.

\section{Acknowledgements}

This project was funded by the Deanship of Scientific Research (DSR), at King Abdulaziz University, Jeddah, under grants No. (G-1436-290-422). The authors, therefore, acknowledge with thank DSR for technical and financial support.

\section{References}

[1] SCENIHR (2015) Scientific Committee on Emerging and Newly Identified Health Risks: Potential Health Effects of Exposure to Electromagnetic Fields (EMF).

http://ec.europa.eu/health/scientific_committees/emerging/docs/scenihr_o_041.pdf 
[2] Baan, R., Grosse, Y., Lauby-Secretan, B., et al. (2011) Carcinogenicity of Radiofrequency Electromagnetic Fields. The Lancet Oncology, 12, 624-626. http://dx.doi.org/10.1016/S1470-2045(11)70147-4

[3] Brenner, D.J., Doll, R., Goodhead, D.T., et al. (2003) Cancer Risks Attributable to Low Doses of Ionizing Radiation: Assessing What We Really Know. Proceedings of the National Academy of Sciences of the United States of America, 100, 13761-13766. http://dx.doi.org/10.1073/pnas.2235592100

[4] Volkow, N.D., Tomasi, D., Wang, G.J., et al. (2011) Effects of Cell Phone Radiofrequency Signal Exposure on Brain Glucose Metabolism. JAMA, 305, 808-813. http://dx.doi.org/10.1001/jama.2011.186

[5] Kwon, M.S., Vorobyev, V., Kännälä, S., et al. (2011) GSM Mobile Phone Radiation Suppresses Brain Glucose Metabolism. Journal of Cerebral Blood Flow and Metabolism, 31, 2293-2301. http://dx.doi.org/10.1038/jcbfm.2011.128

[6] Kwon, M.S., Vorobyev, V., Kännälä, S., et al. (2012) No Effects of Short-Term GSM Mobile Phone Radiation on Cerebral Blood Flow Measured Using Positron Emission Tomography. Bioelectromagnetics, 33, 247-256. http://dx.doi.org/10.1002/bem.20702

[7] Hardell, L. and Sage, C. (2008) Biological Effects from Electromagnetic Field Exposure and Public Exposure Standards. Biomedicine \& Pharmacotherapy, 62, 104-109. http://dx.doi.org/10.1016/j.biopha.2007.12.004

[8] Hardell, L., Carlberg, M., Soderqvist, F. and Mild, K.H. (2013) Case-Control Study of the Association between Malignant Brain Tumours Diagnosed between 2007 and 2009 and Mobile and Cordless Phone Use. International Journal of Oncology, 43, 1833-1845. http://dx.doi.org/10.3892/ijo.2013.2111

[9] Söderqvist, F., Hardell, L., Carlberg, M. and Mild, K.H. (2007) Ownership and Use of Wireless Telephones: A Population-Based Study of Swedish Children Aged 7-14 Years. BMC Public Health, 7, Article 105. http://dx.doi.org/10.1186/1471-2458-7-105

[10] iPhone 4 Important Product Information Guide, June 7th, 2013; Safety and product information. Blackberry Bold 9900/9930 Smartphones, June 7th, 2013.

[11] Economy. KSA Tops World's Mobile Phone Users. 2014. http://www.globalresearch.ca/smart-meter-dangers-the-health-hazards-of-wireless-electromagnetic-radiation-exposure/ $\underline{31891}$

[12] Moussa, S., Alshammari, A., Gada Alshammari, G., Alshammar, K., Alanzi, M., Alanzi, N. and Alshammari, Z. (2013) Pattern of Thyroid Disease in Hail Region, Saudi Arabia. International Journal of Science and Research (IJSR), 5, 276-282.

[13] Hussain, F., Iqbal, S., Mehmood, A., Bazarbashi, S., ElHassan, T. and Chaudhri, N. (2013) The Incidence of Thyroid Cancer in the Kingdom of Saudi Arabia, 2000-2010. Hematology/Oncology and Stem Cell Therapy, 6, 58-64. http://dx.doi.org/10.1016/j.hemonc.2013.05.004

[14] Koyu, A., Cesur, G., Ozguner, F., Akdogan, M., Mollaoglu, H. and Ozen, S. (2005) Effects of 900 MHz Electromagnetic Field on TSH and Thyroid Hormones in Rats. Toxicology Letters, 157, 257-262. http://dx.doi.org/10.1016/j.toxlet.2005.03.006

[15] International Agency for Research on Cancer (2013) Non-Ionizing Radiation, Part 2: Radiofrequency Electromagnetic Fields Exit Disclaimer Exit Disclaimer. IARC Monographs on the Evaluation of Carcinogenic Risks to Humans, Volume 102. IARC, Lyon.

[16] Lamfon, H.A. (2008) Thyroid Disorders in Makkah, Saudi Arabia. Ozean Journal of Applied Sciences, 1, 55-58.

[17] Mortavazi, S., Habib, A., Ganj-Karami, A., Samimi-Doost, R., Pour-Abedi, A. and Babaie, A. (2009) Alterations in TSH and Thyroid Hormones following Mobile Phone Use. Oman Medical Journal, 24, 274-278.

[18] Esmekaya, M.A., Seyhan, N. and Ömeroglu, S. (2010) Pulse Modulated 900 MHz Radiation Induces Hypothyroidism and Apoptosis in Thyroid Cells: A Light, Electron Microscopy and Immunohistochemical Study. International Journal of Radiation Biology, 86, 1106-1116. http://dx.doi.org/10.3109/09553002.2010.502960

[19] Lonn, S., Ahlbom, A., et al. (2004) Mobile Phone Use and the Risk of Acoustic Neuroma. Epidemiology, 15, $653-659$. http://dx.doi.org/10.1097/01.ede.0000142519.00772.bf

[20] Gandhi, O.P., Morgan, L.L., De Salles, A.A., Han, Y.-Y., Herberman, R.B. and Davis, D.L. (2012) Exposure Limits: The Underestimation of Absorbed Cell Phone Radiation, Especially in Children. Electromagnetic Biology and Medicine, 31, 34-51. http://dx.doi.org/10.3109/15368378.2011.622827

[21] Hilly, O., Silva, V., Mizrachi, A., Ariel, O., Raiter, A., Hauptman, Y., Hardy, B. and Feinmesser, R. (2013) Effect of Non-Ionizing Electromagnetic Radiation at Mobile Phone Frequency on Human Thyroid Cells. Abstract from the World Thyroid Cancer Congress in Toronto. 


\section{Submit or recommend next manuscript to SCIRP and we will provide best service for you:}

Accepting pre-submission inquiries through Email, Facebook, Linkedin, Twitter, etc A wide selection of journals (inclusive of 9 subjects, more than 200 journals)

Providing a 24-hour high-quality service

User-friendly online submission system

Fair and swift peer-review system

Efficient typesetting and proofreading procedure

Display of the result of downloads and visits, as well as the number of cited articles

Maximum dissemination of your research work

Submit your manuscript at: http://papersubmission.scirp.org/ 